\title{
Activity of epigenetic inhibitors against Babesia divergens.
}

\author{
Leen N. Vanheer ${ }^{1, \#}$, Björn F.C. Kafsack ${ }^{1, *}$
}

${ }^{1}$ Department of Microbiology \& Immunology, Weill Cornell Medicine, New York, NY, USA

\# current affiliation: London Interdisciplinary Doctoral Programme (LIDo)

* please address correspondence to bkafsack@med.cornell.edu

\section{ABSTRACT}

Babesiosis in a tick-borne parasitic disease of humans and livestock, that has dramatically increased in frequency and geographical range over the past few decades. Infection of cattle often causes large economic losses, and human infection can be fatal in immunocompromised patients. Unlike for malaria, another disease caused by hemoprotozoan parasites, limited treatment options exist for Babesia infections. As epigenetic regulation is a promising target for new anti-parasitic drugs, we screened 324 epigenetic inhibitors against Babesia divergens blood stages and identified $75(23 \%)$ and 17 (5\%) compounds that displayed $\geq 90 \%$ inhibition at $10 \mu \mathrm{M}$ and $1 \mu \mathrm{M}$, respectively, including over a dozen compounds with activity in the low nanomolar range. We observed differential activity of some inhibitor classes against Babesia divergens and Plasmodium falciparum parasites and identified pairs of compounds with a high difference in activity, despite a high similarity in chemical structure, highlighting new insights into the development of epigenetic inhibitors as anti-parasitic drugs.

\section{INTRODUCTION}

Babesiosis is an emerging parasitic disease caused by the intra-erythrocytic Babesia parasite and has many clinical features similar to malaria infection. Babesia infections in cattle are widespread and lead to economic losses through death, reduction in meat and milk yield, and the cost of control measures. More than 100 Babesia species have been identified but only a few infect humans. However, human babesiosis is an increasing concern worldwide, as the number of reported cases have increased over the last decades and the geographical rage of transmission has expanded 1,2. In Europe, Babesia divergens is responsible for most human babesiosis cases ${ }^{3}$. In the US, the majority of human Babesia infections is caused by Babesia microti, although cases of $B$. divergens-like organisms have been reported as well ${ }^{4}$. Transmission occurs through the bite of an infected tick or occasionally through blood transfusion, which has prompted the screening of the blood supply for Babesia parasites in an increasing number of U.S. states ${ }^{5}$. Symptomatic human babesiosis is manifested by malarialike symptoms, such as fever and general malaise. Treatment recommendations for human 
babesiosis are a combination of atovaquone and azithromycin for mild to moderate babesiosis and clindamycin plus quinine for severe infection ${ }^{6}$. However, for immunocompromised patients, cases of treatment failure for both regimens have been reported ${ }^{7,8}$ and babesiosis can lead to organ failure and death. Asplenic patients, in particular, are at high risk for relapsing infections and require long antimicrobial treatment ${ }^{9}$. Recently, tafenoquine, a newly FDAapproved drug for malaria treatment, showed activity against Babesia microti in mice but further studies are needed ${ }^{10}$. As treatment options for relapsing Babesia infection are limited, research into new drugs for babesiosis is critical.

In eukaryotes, epigenetic regulation of gene expression, mediated by small modifications of nucleosomes and on DNA itself, has been found to be critical for cellular homeostasis and differentiation ${ }^{11}$. In a recent screen of 324 commercially available epigenetic inhibitors against Plasmodium falciparum ${ }^{12}$, we showed that 54 compounds exhibited $\geq 50 \%$ inhibition at $1 \mu \mathrm{M}$ in vitro, suggesting that the epigenetic machinery could be a promising novel drug target. Since Plasmodium and Babesia are related parasite species with similarly complex life cycles that share much of the epigenetic regulatory machinery, we decided to determine the activity of these epigenetic inhibitors against Babesia divergens, for which an in vitro culture system and drug assays are established.

\section{METHODS}

Commercially available libraries of 324 epigenetic inhibitors from Selleckchem (Houston, TX) and Cayman Chemicals (Ann Arbor, MI) were purchased. Libraries were aliquoted and diluted in DMSO to $2 \mathrm{mM}$ and $0.2 \mathrm{mM}$ in V-bottom 96 -well plate and stored at $-80^{\circ} \mathrm{C}$.

Babesia divergens (Bd Rouen 1987 strain ${ }^{13}$ ) was grown in vitro in human A+ RBC at low parasitemia. Cultures were flushed with $90 \%$ nitrogen, $5 \%$ oxygen and $5 \%$ carbon dioxide and cultured at $37^{\circ} \mathrm{C}$. SYBR Green based growth assays were used to determine in vitro activity of the epigenetic inhibitors against $B$. divergens ${ }^{14,15}$. Briefly, flat-bottom 96 -well plates at a total of $200 \mu \mathrm{L}$ per well and $0.5 \%$ DMSO, at a final $5 \%$ hematocrit, $0.5 \%$ parasitemia for $B$. divergens were incubated at $37^{\circ} \mathrm{C}$ for 72 hours and thereafter frozen at $-80^{\circ} \mathrm{C}$. Upon thawing, $100 \mu \mathrm{L}$ of SYBR Green (ThermoFisher) diluted in lysis buffer $(0.2 \mu \mathrm{L} 10,000 X$ SYBR Green per mL lysis buffer) was added to each well and plates were shaken in the dark at room temperature for 1 hour. Fluorescence was then measured using a Molecular Devices SpectraMax ID5 plate reader. Values were normalized to solvent-treated controls (included in triplicate on each plate). EC50 values were calculated using the nImLS function of the minpack.Im package (v1.2-1) of the R statistical package (v3.6.0). 
Protein sequences of histone modifying enzymes were retrieved from PlasmoDB and PiroplasmaDB 16,17 . Orthologs were identified using annotated ortholog groups as well as reciprocal BLAST searches. NCBI Conserved Domain Search 18 was used to identify conserved protein domains. Protein sequences were aligned using MUSCLE ${ }^{19}$ and visualized using MView ${ }^{20}$. In cases where two consecutive genes were identified as orthologs, the geneID for the ortholog containing the catalytic domain was indicated as the ortholog.

Structural feature (SkelSphere) analysis and Activity Cliff Analysis were performed using Osiris DataWarrior v5.2.1, at $80 \%$ chemical structure similarity cut-off. Structure-Activity Landscape Index (SALI) values ${ }^{21}$ were calculated as:

$S A L I I, J=((|A i-A j|) /(1-\operatorname{sim}(i, j)))$

in which $A i$ and $A j$ are the activities of compounds $i$ and $j$, and $\operatorname{sim}(I, j)$ is the similarity coefficient between the two molecules.

\section{RESULTS AND DISCUSSION}

\section{Evolutionary conservation of epigenetic modifying enzymes in piroplasmid parasites.}

Among eukaryotes, the most common epigenetic modifications are acetylation of histone lysine residues, methylation of histone lysine and arginine residues, and methylation of deoxycytidine on DNA. We were able to identify orthologs for most of the enzymes classes that place and remove these marks in the genomes of piroplasmid parasites, which includes Babesia and Theileria species (Figure 1, Supplemental Table 1, Supplemental Dataset 1). Orthologs to seven of the eleven $\underline{\text { Su}}(\mathrm{var}) 3-9 / \underline{E}$ nhancer of Zeste/_Trithorax (SET)-domain-containing lysinespecific histone methyltransferases (KMT) present in $P$. falciparum could be identified in at least one piroplasmid genome. Orthologs of PfSET4 and PfSET5 were absent in the entire clade while an ortholog to PfSET6 could only be identified in B. microti. Orthologs to PfSET9 could be identified in all piroplasmida genomes but are missing key residues within the catalytic SET domain thus making it unlikely that these have retained methyltransferase activity. Most piroplasmid genomes also retain two additional trithorax-like SET-domain proteins found in other apicomplexan parasites that were lost in malaria parasites. Histone demethylases were notably reduced compared to $P$. falciparum, with $B$. divergens and $B$. bovis only encoding a single member of the Jumonji and LSD demethylase families.

All three the histone arginine methyltransferases (RMTs) in P. falciparum had orthologs in $B$. divergens, but the PRTM3 ortholog was lost outside the Babesia sensu stricto clade (represented by $B$. bovis and $B$. divergens). Histone acetyltransferases (HATs) and 
deacetylases (HDACs) were generally conserved between malaria parasites and the piroplasmida. Notable is the absence of Sir2A from all piroplasmid genomes and loss of HAT1 from the Babesia sensu stricto clade. An ortholog of a proposed Cytosine-5 DNA methyltransferase in Plasmodium falciparum ${ }^{22}$ is present in Theileria equi but could not be identified in the other genomes examined.

\section{Activity of epigenetic inhibitors against Babesia divergens.}

Given these differences in histone modifying enzymes between $P$. falciparum and the piroplasms, we decided to test the susceptibility of $B$. divergens to a library of epigenetic inhibitors previously screened against $P$. falciparum ${ }^{12}$. Of the 324 compounds tested, 125 (39\%) showed $\geq 50 \%$ inhibition at $10 \mu \mathrm{M}$ against $B$. divergens blood stages, of which $46(14 \%)$ retained greater than half-maximal activity at $1 \mu \mathrm{M}$ (Figure $2 \mathrm{~A}$, Supplemental Figure 1 and Table 2, Supplemental Dataset 2). 75 (23\%) and 17 (5\%) of compounds exhibited greater than $90 \%$ inhibition at $10 \mu \mathrm{M}$ and $1 \mu \mathrm{M}$, respectively. Dose-response curves were performed for 17 compounds with sub-micromolar EC90 values (Figure 2B). Of these, the HDAC inhibitors quisinostat and apicidin were the most potent compounds, with EC50 values as low as $5-6$ $\mathrm{nM}$. These top hits included two FDA-approved drugs mitomycin $\mathrm{C}$ and panobinostat with EC50 values of $63 \mathrm{nM}$ and $27 \mathrm{nM}$, respectively. Peak plasma concentration of panobinostat dosage indicated for treatment of multiple myeloma only correspond to EC75 for Babesia making it an unlikely candidate for treatment ${ }^{23,24}$. Mitomycin $C$ is a CpG DNA crosslinking agent indicated, indicated for gastric and pancreatic adenocarcinoma treatment and was recently also approved for low-grade upper tract urothelial cancer. ${ }^{25}$. Intravenous administration during chemotherapy leads to plasma concentration of $5 \mu \mathrm{M}^{26}$, around 20-fold higher than its EC90 value against $B$. divergens. We previously determined toxicity of selected compounds against human HepG2 cells ${ }^{12}$. Several compounds displayed only moderate toxicity against HepG2 cells even at $1 \mu \mathrm{M}$ (Figure 2B). This drug screen identifies promising compounds for additional SAR studies for possible use as a new class of anti-Babesia drugs.

\section{Differential activity of epigenetic inhibitors against $\boldsymbol{B}$. divergens and $\boldsymbol{P}$. falciparum.}

Next, we compared these results to our recently completed screen of this library against $P$. falciparum blood stages ${ }^{12}$. A similar number of compounds had $>50 \%$ inhibition at $1 \mu \mathrm{M}$ against both species (46 against $B$. divergens compared to 54 against $P$. falciparum). For both species, compounds targeting histone methylation, deacteylation, demethylation or phosphorylation were the most active, while compounds targeting histone acetylation, PARPylation, histone reader domains, DNA methylation or other pathways had little to no activity (Supplemental Table 1). 
Twenty-five compounds with $>50 \%$ inhibition at $1 \mu \mathrm{M}$ against one species exhibited greater than two-fold difference in activity in the other (Figure 3). HDAC inhibitors were generally less active against $B$. divergens than against $P$. falciparum, with $18 \%$ of the 85 HDAC inhibitors in the library showing $\geq 90 \%$ inhibition at $1 \mu \mathrm{M}$ against $P$. falciparum versus only $8 \%$ for $B$. divergens (Supplemental Table) 2. Interestingly, several HDAC inhibitors with high differential activity target the human HDAC1 (class I) or HDAC6 (class IIb), suggesting that the HDACs may be more divergent from the human enzymes in $B$. divergens than in $P$. falciparum. An additional 25 compounds exhibited greater than $75 \%$ inhibition against both $P$. falciparum and $B$. divergens. Thirteen of these were HDAC inhibitors many of which have activity against multiple HDAC classes. Surprisingly, of the $15 \mathrm{HMT}$ inhibitors in Figure 3B, the four compounds with greater activity against $B$. divergens target either ethery the H3K79 HMT DOT1L or the H3K27 HMT EZH1/2 in humans, orthologs to which are absent from both species. As in our previous study, the DNMT inhibitor SGI-1027 was also among the most active compounds against $B$. divergens, despite no identifiable DNMT ortholog in Babesia species and PfDNMT being dispensable for asexual growth ${ }^{27}$, suggesting that SGI-1027 likely has one or more alternative targets.

\section{Similarity and activity cliff analysis of activity against $\boldsymbol{B}$. divergens and $\boldsymbol{P}$. falciparum.}

Structural feature analysis of all 324 unique compounds revealed five clusters of four compounds or more with $>80 \%$ structural similarity (Supplemental Figure 2), including seven HDAC inhibitors with a common hydroxamate-based scaffold, seven HMT inhibitors sharing a common diaminoquinazoline backbone (Figure 5) and three HMT inhibitors an 1H-indazole-4carboxamide scaffold (Figure 4B). Activity Cliff analysis identifies pairs with high differential activity, despite high structural similarity. Delta activity and SALI values are plotted for all pairs of the library in Supplemental Figure 3. Compound pairs of interest have $>50 \%$ delta activity and $>80 \%$ structural similarity (Figure $4 \mathrm{~A}$ ). Twelve pairs were activity cliffs in both $P$. falciparum and $B$. divergens, while three only had more than $50 \%$ delta activity in $B$. divergens and 4 only in $P$. falciparum.

The HMT inhibitor UNC1999 displays an activity cliff for activity against $B$. divergens when paired with GK343 and GSK503, despite the former having 91\% structural similarity (Figure 4B). Interestingly, the IC50 values for mammalian EZH2 enzyme inhibition are similar for all three compounds, while UNC1999 is the only compound with potent EZH1 inhibition as well. Kinase inhibitors belinostat and oxamflatin show activity cliffs for both species (Figure 4C). Additional structural comparisons of the remaining activity cliff pairs can be found in 
Supplemental Figure 4. These activity cliff pairs provide insight into the structural features that confer activity against $P$. falciparum and $B$. divergens.

\section{Differential HMT inhibitors with a diaminoquinazoline backbone.}

Seven HMT inhibitors of the SET3 HMT G9a share a diaminoquinazoline backbone ${ }^{28-33}$. Figure $5 \mathrm{~A}$ shows pairs with $>60 \%$ similarity and $>50 \%$ delta activity at $1 \mu \mathrm{M}$ in both species. For Babesia divergens, the side group on position 4 of the diaminoquinazoline scaffold seemed to have the most effect on compound activity (Figure 5B). A cyclohexylmethyl-4-piperidylamine side group (UNC0631) showed the highest activity, while the EC50 value increased 5-6 times when changing to a cyclohexyl-4-piperidylamine (UNC0646) or 1-benzyl-4-piperidylamine (BIX01294) side group. Substituting the ring structure with an isopropyl group (UNC0638 and UNC0642) further decreased the remaining activity by half. Activity is completely lost when the side group consists of a lone 4-piperidylamine (UNC0224).

Previous SAR studies of diaminoquinazolines methyltransferase inhibitors have been performed for $P$. falciparum, ${ }^{34,35}$. We confirmed that substituting the 1-benzyl-4-piperidylamine of BIX01294 on position 4 of the diaminoquinazoline scaffold with a cyclohexylmethyl-4piperidylamine (UNC0631) or a cyclohexyl-4-piperidylamine (UNC0646) reduced the activity against $P$. falciparum (Supplemental Figure 5). However, in disagreement with previous findings, the substitution with a 1-isopropyl-4-piperidylamine (UNC0642 and UNC0638) did not impact the activity against $P$. falciparum.

It was previously reported that a lysine mimetic side group on position 7 of the diaminoquinazoline scaffold lacks activity against $P$. falciparum, despite exhibiting potent activity against G9a due to interactions in the lysine binding channel of this enzyme. We confirmed that a dimethylpropylamine side group (UNC0224) loses activity as previously reported, but interestingly, we found the lysine mimetic side groups 1-propylpyrrolidine (UNC0642 and UNC0638) and 1-propylpiperidine (UNC0631 and UNC0646) retained most of their activity. This suggests that compounds with a lysine mimetic side group on position 7 of the diaminoquinazoline scaffold can inhibit $P$. falciparum only if combined with certain side groups on position 2 and 4 of the scaffold.

Three of the diaminoquinazoline compounds have a high differential activity against both species, showing 17-24 times more activity against $P$. falciparum (Figure 5C). As two of these compounds (UNC0642 and UNC0638) share a 1-isopropyl-4-piperidylamine group on position 4 and a 1-propylpyrrolidine group on position 7, these might contribute to this difference in 
activity. As the closest related $P$. falciparum HMT to HsG9a is PfSET3, it is possible that the binding site on the HMT enzyme for these three compounds is more divergent from HsG9a in BdSET3 than in PfSET3.

Overall, we show that epigenetic enzymes may be a promising novel target in Babesia divergens. Our library of 324 epigenetic inhibitors includes 19 pairs of compounds with high delta activity despite high structural similarity, which provide insight into the structural features that confer activity against $P$. falciparum and $B$. divergens. Multiple diaminoquinazoline backbone HMT inhibitors show highly active against both species tested, with UNC0631 displaying a low nanomolar range EC50 value against both $P$. falciparum and $B$. divergens, while UNC0224 is inactive against both species despite minor structural differences with the active diaminoquinazoline compounds.

ACKNOWLEDGEMENTS: We thank the High Throughput and Spectroscopy Resource Center at Rockefeller University for technical assistance, and Elisabeth Martinez (UT Southwestern) for additional JIB-04 inhibitor. We also thank Laura Kirkman for providing the $B$. divergens strain and valuable feedback on the manuscript. This work was supported by a Bohmfalk Charitable Trust Research Grant and NIH 1R01Al141965 and 1R01Al138499 to BK, and a Belgian American Educational Foundation post-doctoral fellowship to LV.

\section{REFERENCES:}

(1) Gray, E. B.; Herwaldt, B. L. Babesiosis Surveillance - United States, 2011-2015. MMWR Surveill Summ 2019 2019, No. 68, 1-11 DOI: http://dx.doi.org/10.15585/mmwr.ss6806a1external icon.

(2) Hildebrandt, A.; Gray, J. S.; Hunfeld, K. P. Human Babesiosis in Europe: what clinicians need to know. Infection 2013, 41 (6), 1057-1072 DOI: 10.1007/s15010013-0526-8.

(3) Krause, P. J. Human babesiosis. International Journal for Parasitology 2019, 49 (2), 165-174 DOI: 10.1016/j.jpara.2018.11.007.

(4) Herwaldt, B.; de Bruyn, G.; Norman, P.; Mary, H.; Kathryn, L.; Susan, S.; Thomas, F.; David, P.; Ajit, L. Babesia divergens-like infection, Washington State. Emerging Infectious Diseases 2004, 1-8.

(5) US Federal Drug Administration, Center for Biologics Evaluation and Research; 2019. Recommendations for Reducing the Risk of Transfusion-Transmitted Babesiosis Guidance for Industry.

(6) Wormser, G. P.; Dattwyler, D. R.; Shapiro, S. E.; John, H.; Allen, S.; Mark, K.; Krause, P. J.; Johan, B.; Franc, S.; Gerold, S.; et al. The Clinical Assessment, Treatment, and Prevention of Lyme Disease, Human Granulocytic Anaplasmosis, and Babesiosis: Clinical Practice Guidelines by the Infectious Diseases Society of America. IDSA guidelines 2006, 1-47. 
bioRxiv preprint doi: https://doi.org/10.1101/2020.12.04.411777; this version posted December 4,2020 . The copyright holder for this preprint (which was not certified by peer review) is the author/funder, who has granted bioRxiv a license to display the preprint in perpetuity. It is made available under aCC-BY-NC 4.0 International license.

(7) Simon, M. S.; Westblade, L. F.; Dziedziech, A.; Visone, J. E.; Furman, R. R.; Jenkins, S. G.; Schuetz, A. N.; Kirkman, L. A. Clinical and Molecular Evidence of Atovaquone and Azithromycin Resistance in Relapsed Babesia microti Infection Associated With Rituximab and Chronic Lymphocytic Leukemia. Clinical Infectious Diseases 2017, 65 (7), 1222-1225 DOI: 10.1093/cid/cix477.

(8) Wormser, G. P.; Prasad, A.; Neuhaus, E.; Joshi, S.; Nowakowski, J.; Nelson, J.; Mittleman, A.; Aguero Rosenfeld, M.; Topal, J.; Krause, P. J. Emergence of Resistance to Azithromycin-Atovaquone in Immunocompromised Patients with Babesia microtilnfection. Clinical Infectious Diseases 2010, 50 (3), 381-386 DOI: 10.1086/649859.

(9) Krause, P. J.; Gewurz, B. E.; Hill, D.; Marty, F. M.; Vannier, E.; Foppa, I. M.; Furman, R. R.; Neuhaus, E.; Skowron, G.; Gupta, S.; et al. Persistent and Relapsing Babesiosis in Immunocompromised Patients. Clinical Infectious Diseases 2008, 46 (3), 370-376 DOI: 10.1086/525852.

(10) Mordue, D. G.; Wormser, G. P. Could the Drug Tafenoquine Revolutionize Treatment of Babesia microti Infection? J INFECT DIS 2019, 220 (3), 442-447 DOI: 10.1093/infdis/jiz119.

(11) Gibney, E.; Nolan, C. Epigenetics and gene expression. Heredity 2010, 105 (1), 4-13 DOI: $10.1038 /$ hdy.2010.54.

(12) Vanheer, L. N.; Zhang, H.; Lin, G.; Kafsack, B. F. C. Activity of Epigenetic Inhibitors against Plasmodium falciparum Asexual and Sexual Blood Stages. Antimicrobial Agents and Chemotherapy 2020, 64 (7), a02523-19 DOI: 10.1128/AAC.02523-19.

(13) Gorenflot, A.; Brasseur, P.; Precigout, E.; M, L.; Marchand, A.; Schrevel, J. Cytological and immunological responses to Babesia divergens in different hosts: ox, gerbil, man. Parasitol Res 1991, 1-10.

(14) Smilkstein, M.; Sriwilaijaroen, N.; Kelly, J. X.; Wilairat, P.; Riscoe, M. Simple and inexpensive fluorescence-based technique for high-throughput antimalarial drug screening. Antimicrobial Agents and Chemotherapy 2004, 48 (5), 1803-1806 DOI: 10.1128/AAC.48.5.1803-1806.2004.

(15) Rizk, M. A.; El-Sayed, S. A. E.-S.; AbouLaila, M.; Tuvshintulga, B.; Yokoyama, N.; Igarashi, I. Large-scale drug screening against Babesia divergens parasite using a fluorescence-based high-throughput screening assay. Veterinary Parasitology 2016, 227, 93-97 DOI: 10.1016/j.vetpar.2016.07.032.

(16) Aurrecoechea, C.; Brestelli, J.; Brunk, B. P.; Dommer, J.; Fischer, S.; Gajria, B.; Gao, X.; Gingle, A.; Grant, G.; Harb, O. S.; et al. PlasmoDB: a functional genomic database for malaria parasites. Nucleic Acids Res 2009, 37 (Database), D539-D543 DOI: $10.1093 /$ nar/gkn814.

(17) Aurrecoechea, C.; Barreto, A.; Brestelli, J.; Brunk, B. P.; Cade, S.; Doherty, R.; Fischer, S.; Gajria, B.; Gao, X.; Gingle, A.; et al. EuPathDB: The Eukaryotic Pathogen database. Nucleic Acids Res 2012, 41 (D1), D684-D691 DOI: 10.1093/nar/gks1113.

(18) Marchler-Bauer, A.; Bryant, S. H. CD-Search: protein domain annotations on the fly. Nucleic Acids Res 2004, 32 (Web Server), W327-W331 DOI: 10.1093/nar/gkh454.

(19) Edgar, R. C. MUSCLE: multiple sequence alignment with high accuracy and high throughput. Nucleic Acids Res 2004, 32 (5), 1792-1797 DOI: 10.1093/nar/gkh340.

(20) Brown, N.; Leroy, C.; Sander, C. MView: a web-compatible database search or multiple alignment viewer. Bioinformatics 1998, 1-2.

(21) Guha, R.; Van Drie, J. H. Structure-Activity Landscape Index: Identifying and Quantifying Activity Cliffs. J. Chem. Inf. Model 2008, No. 48, 646-658 DOI: 10.1021/ci7004093.

(22) Ponts, N.; Fu, L.; Harris, E. Y.; Zhang, J.; Chung, D.-W. D.; Cervantes, M. C.; Prudhomme, J.; Atanasova-Penichon, V.; Zehraoui, E.; Bunnik, E. M.; et al. Genomewide Mapping of DNA Methylation in the Human Malaria Parasite Plasmodium 
bioRxiv preprint doi: https://doi.org/10.1101/2020.12.04.411777; this version posted December 4,2020 . The copyright holder for this preprint (which was not certified by peer review) is the author/funder, who has granted bioRxiv a license to display the preprint in perpetuity. It is made available under aCC-BY-NC 4.0 International license.

falciparum. Cell Host Microbe 2013, 14 (6), 696-706 DOI:

10.1016/j.chom.2013.11.007.

(23) Anne, M.; de Sammartino, D.; Barginear, M.; Budman, D. Profile of panobinostat and its potential for treatment in solid tumors: an update. OTT 2013, 1613-12 DOI: 10.2147/OTT.S30773.

(24) DeAngelo, D. J.; Spencer, A.; Bhalla, K. N.; Prince, H. M.; Fischer, T.; Kindler, T.; Giles, F. J.; Scott, J. W.; Parker, K.; Liu, A.; et al. Phase la/ll, two-arm, open-label, dose-escalation study of oral panobinostat administered via two dosing schedules in patients with advanced hematologic malignancies. Leukemia 2019, 27 (8), 1-9 DOI: 10.1038/leu.2013.38.

(25) Macdonald, J.; Schein, P.; Woolley, P.; Smythe, T.; Ueno, W.; Hoth, D.; Smith, F.; Boiron, M.; Gisselbrecht, C.; Brunet, R.; et al. 5-Fluorouracll, Doxorubicin, and Mitomycin (FAM) Combination Chemotherapy for Advanced Gastric Cancer. Annals of Internal Medicine 1980, 93 (4), 1-4.

(26) Bedford Laboratories. MITOMYCIN - mitomycin injection, powder, lyophilized, for solution. Bedford, OH 44146 December 1, 2009, pp 1-9.

(27) Zhang, M.; Wang, C.; Otto, T. D.; Oberstaller, J.; Liao, X.; Adapa, S. R.; Udenze, K.; Bronner, I. F.; Casandra, D.; Mayho, M.; et al. Uncovering the essential genes of the human malaria parasite Plasmodium falciparum by saturation mutagenesis. Science 2018, 360 (6388), eaap7847 DOI: 10.1126/science.aap7847.

(28) Kubicek, S.; O'Sullivan, R. J.; August, E. M.; Hickey, E. R.; Zhang, Q.; Teodoro, M. L.; Rea, S.; Mechtler, K.; Kowalski, J. A.; Homon, C. A.; et al. Reversal of H3K9me2 by a Small-Molecule Inhibitor for the G9a Histone Methyltransferase. Molecular Cell 2007, 25 (3), 473-481 DOI: 10.1016/j.molcel.2007.01.017.

(29) Liu, F.; Allali-Hassani, A.; Siarheyeva, A.; Jadhav, A. Discovery of a 2,4-Diamino-7aminoalkoxyquinazoline as a Potent and Selective Inhibitor of Histone Lysine Methyltransferase G9a. 2009, 1-4 DOI: 10.1021/jm901543m.

(30) Liu, F.; Barsyte-Lovejoy, D.; Allali-Hassani, A.; Frye, S.; Brown, P. Optimization of Cellular Activity of G9a Inhibitors 7-Aminoalkoxy-quinazolines. J. Med. Chem. 2011, 1-12 DOI: 10.1021/jm200903z.

(31) Vedadi, M.; Barsyte-Lovejoy, D.; Liu, F.; Rival-Gervier, S.; Allali-Hassani, A.; Labrie, V.; Wigle, T. J.; DiMaggio, P. A.; Wasney, G. A.; Siarheyeva, A.; et al. A chemical probe selectively inhibits G9a and GLP methyltransferase activity in cells. Nat Chem Biol 2011, 7 (8), 566-574 DOI: 10.1038/nchembio.599.

(32) Liu, F.; Barsyte-Lovejoy, D.; Li, F.; Xiong, Y.; Korboukh, V.; Allali-Hassani, A.; Janzen, W.; Roth, B.; Frye, S.; Arrowsmith, C.; et al. Discovery of an in Vivo Chemical Probe of the Lysine Methyltransferases G9a and GLP. J. Med. Chem. 2013, 1-12 DOI: 10.1021/jm401480r.

(33) Ma, A.; Yu, W.; Li, F.; Bleich, R. M.; Herold, J. M.; Butler, K. V.; Norris, J. L.; Korboukh, V.; Tripathy, A.; Janzen, W. P.; et al. Discovery of a selective, substratecompetitive inhibitor of the lysine methyltransferase SETD8. J. Med. Chem. 2014, 57 (15), 6822-6833 DOI: 10.1021/jm500871s.

(34) Sundriyal, S.; Malmquist, N. A.; Caron, J.; Blundell, S.; Liu, F.; Chen, X.; Srimongkolpithak, N.; Jin, J.; Charman, S. A.; Scherf, A.; et al. Development of Diaminoquinazoline Histone Lysine Methyltransferase Inhibitors as Potent BloodStage Antimalarial Compounds. ChemMedChem 2014, 9 (10), 2360-2373 DOI: 10.1002/cmdc.201402098.

(35) Sundriyal, S.; Chen, P. B.; Lubin, A. S.; Lueg, G. A.; Li, F.; White, A. J. P.; Malmquist, N. A.; Vedadi, M.; Scherf, A.; Fuchter, M. J. Histone lysine methyltransferase structure activity relationships that allow for segregation of G9a inhibition and antiPlasmodium activity. Med. Chem. Commun. 2017, 8 (5), 1069-1092 DOI: 10.1039/C7MD00052A. 


\section{FIGURE LEGENDS}

Figure 1. Conservation of epigenetic writer and eraser enzymes orthologs among the Piroplasmida with $P$. falciparum as an outgroup.

Figure 2. Activity of epigenetic inhibitors against Babesia divergens. (A) 125 compounds with $\geq 50 \%$ inhibition at $10 \mu \mathrm{M}$. Heatmap of mean percent inhibition at 10 and $1 \mu \mathrm{M}$ compared to solvent-treated controls $(n=3)$. Compounds are grouped based on the reported epigenetic process affected in higher eukaryotes: Histone deacetylation (HDAC), histone acetylation (HAT), histone methylation (HMT), Histone Demethylases (HDM), DNA methylation (DNMT), and "Other". (B) Dose response analysis for 17 compounds with sub-micromolar EC50 values $(n=2)$, with corresponding HepG2 inhibition at $1 \mu \mathrm{M}$.

Figure 3. Differential activity of epigenetic inhibitors against $B$. divergens and $\boldsymbol{P}$. falciparum. (A) Scatterplot comparing \%inhibition at $1 \mu \mathrm{M}$ against $B$. divergens and $P$. falciparum. Dotted lines indicate more than 2-fold difference in activity. Compound names are for compounds with more than 2-fold difference in activity and more than $50 \%$ inhibition at 1 $\mu \mathrm{M}$ against one species. An enlarged scatterplot with labelled compound names is displayed for compounds with $\geq 75 \%$ at $1 \mu \mathrm{M}$ against both species. (B) Heatmap of compounds with at least $50 \%$ inhibition at $1 \mu \mathrm{M}$ against one species, ordered by the delta activity (\% Pf inhibition - \% $B d$ inhibition) and grouped by target category.

Figure 4. Activity cliff analysis. (A) Scatterplot of activity cliff pairs with $>50 \%$ delta activity and $>80 \%$ structural similarity (SALI), grouped by species. (B-C) Examples of activity cliff pairs with chemical structures and activity.

Figure 5. Compounds with diaminoquinazoline backbone. (A) Compounds with $>60 \%$ similarity and $>50 \%$ delta activity at $1 \mu \mathrm{M}$. (B) Activity of compounds with diaminoquinazoline backbone against Babesia divergens. (C) Changes in chemical structure that confer differential activity against both species. 


\section{SUPPLEMENTARY FIGURE LEGENDS}

Supplemental Figure 1: Mean percent inhibition of all 324 compounds against $B$. divergens at $10 \mu \mathrm{M}$ and $1 \mu \mathrm{M}$. The dotted and dashed lines indicate $50 \%$ and $90 \%$ inhibition, respectively. Compounds are ordered by increasing activity at $10 \mu \mathrm{M}$. Error bars are standard error of $n=3$.

Supplemental Figure 2: Structural feature similarity landscape. Compounds with $>80 \%$ structural similarity were grouped in Datawarrior (SkelSphere). Color indicates reported epigenetic process targeted in higher eukaryotes.

Supplemental Figure 3: Activity cliff analysis for Babesia divergens at $1 \mu \mathrm{M}$. Scatterplot with each dot representing a pair of compounds in the library. Compound pairs of interest have $>50 \%$ delta activity (dashed line) and $>80 \%$ structural similarity (dotted line).

Supplemental Figure 4: Structural representation of the remaining activity cliff pairs that are displayed in figure $4 \mathrm{~A}$.

Supplemental Figure 5: Activity of compounds with diaminoquinazoline backbone against P. falciparum.

Supplemental Table 1: EC50 Activity of epigenetic inhibitors tested grouped by target category. Percentage of active compounds is indicated in brackets $(n=2-3)$.

Supplemental Table 2: EC90 Activity of epigenetic inhibitors tested grouped by target category. Percentage of active compounds is indicated in brackets $(n=2-3)$.

Supplemental Dataset 1: Gene identifiers of epigenetic writer and reader enzyme orthologs in Figure 1.

Supplemental Dataset 2: Mean percent inhibition of all compounds against B. divergens at $10 \mu \mathrm{M}$ and $1 \mu \mathrm{M}$. 


\section{Writers}

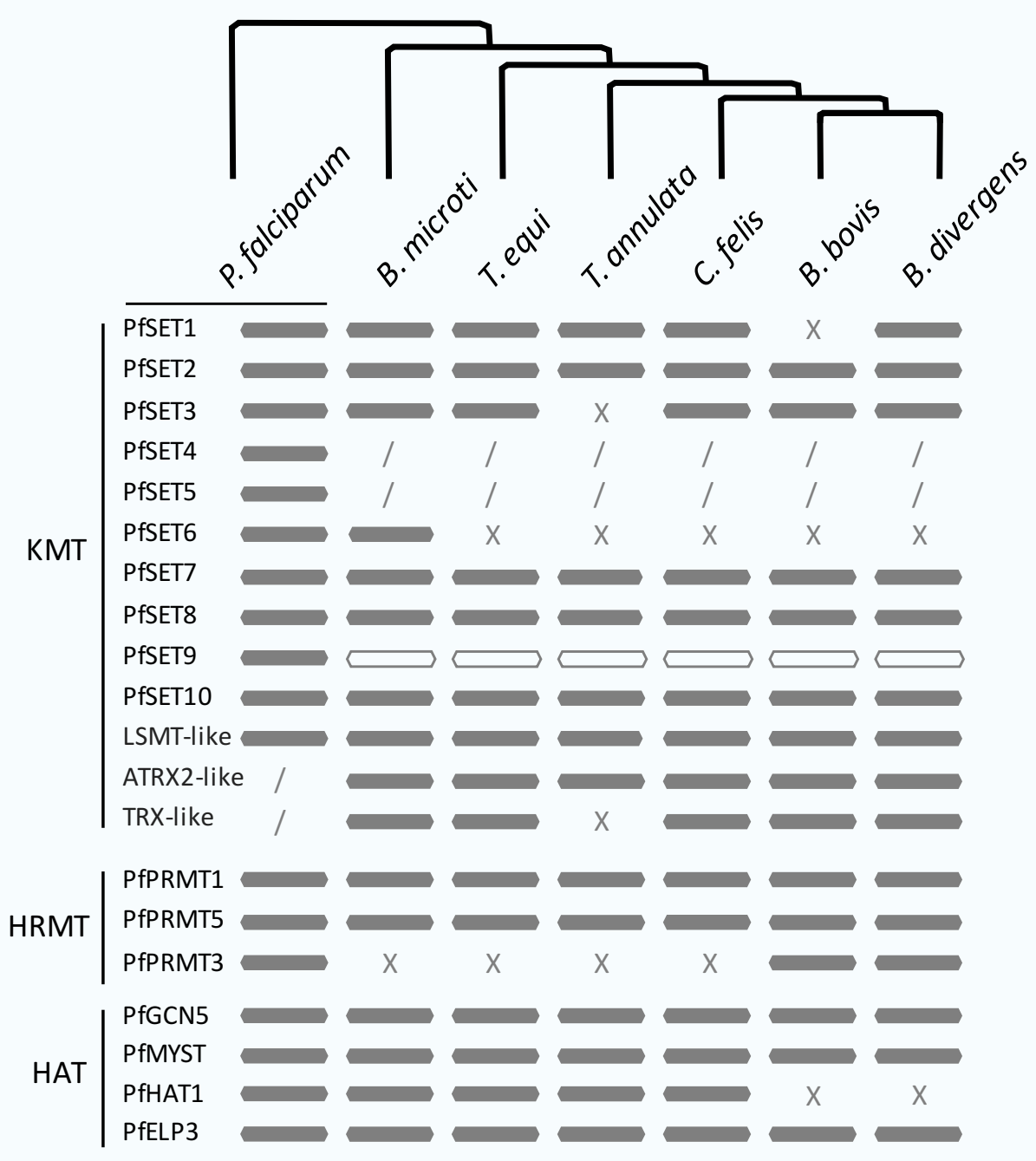

Erasers

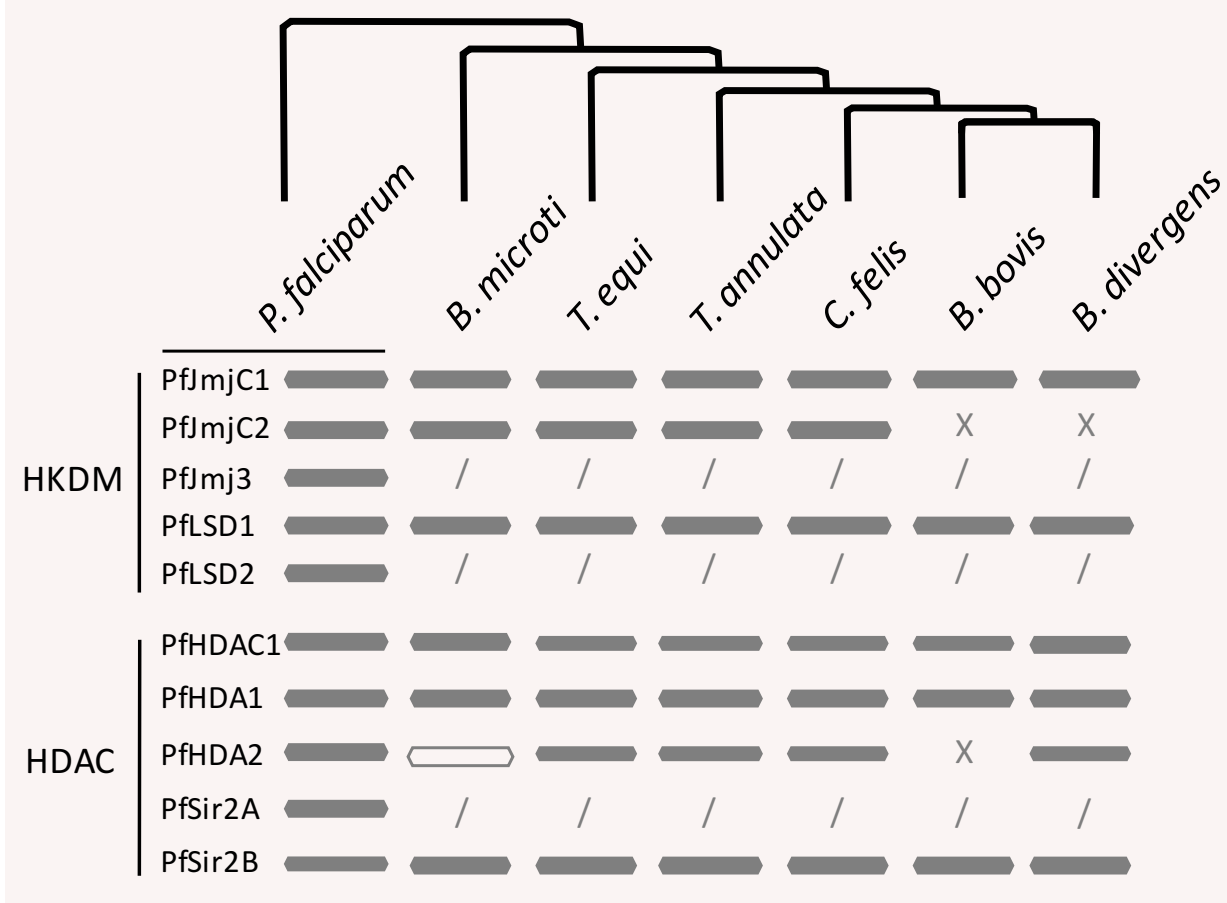

Figure 1. Evolutionary conservation of epigenetic modifying enzymes in piroplasmid parasites. Comparison of epigenetic modifying enzyme orthologs between P. falciparum, B. microti, T. equi, T. annulata, C. felix, B. bovis and $B$. microti, with a representation of the evolutionary relationship between these species. 


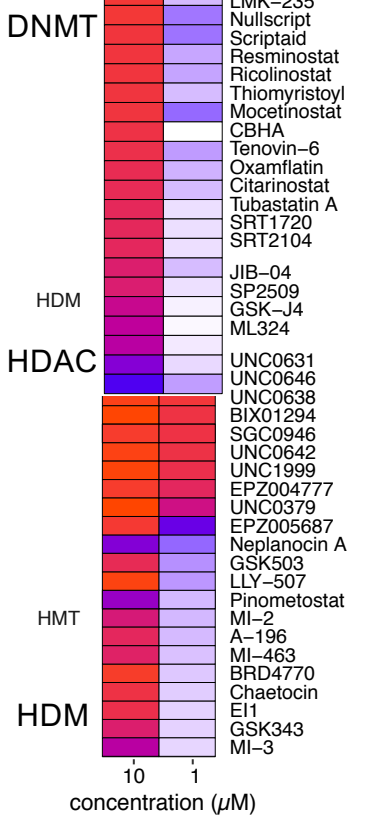

concentration $(\mu \mathrm{M})$
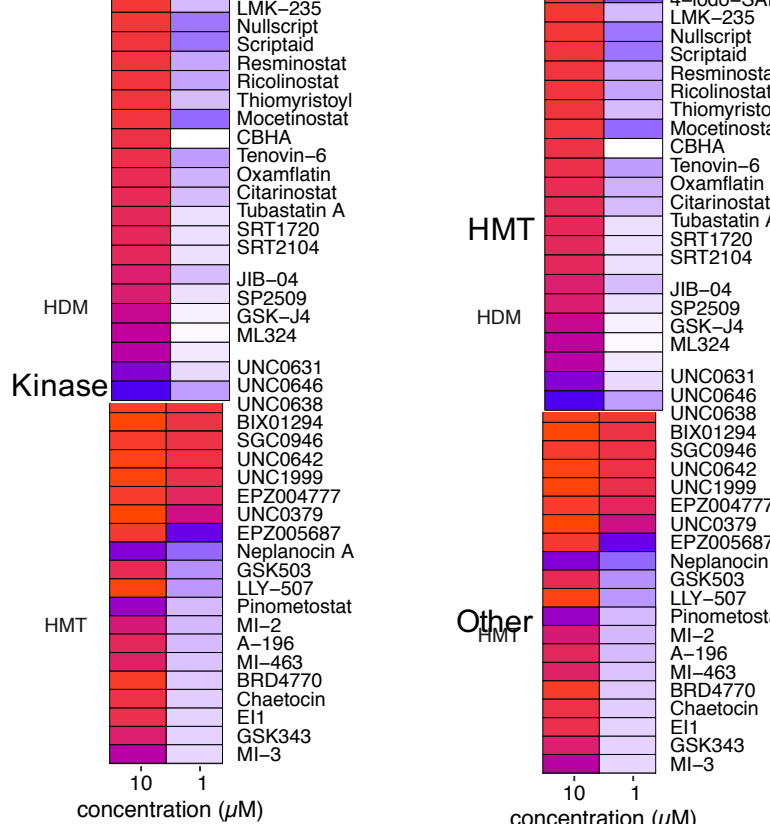

concentration $(\mu \mathrm{M})$

B

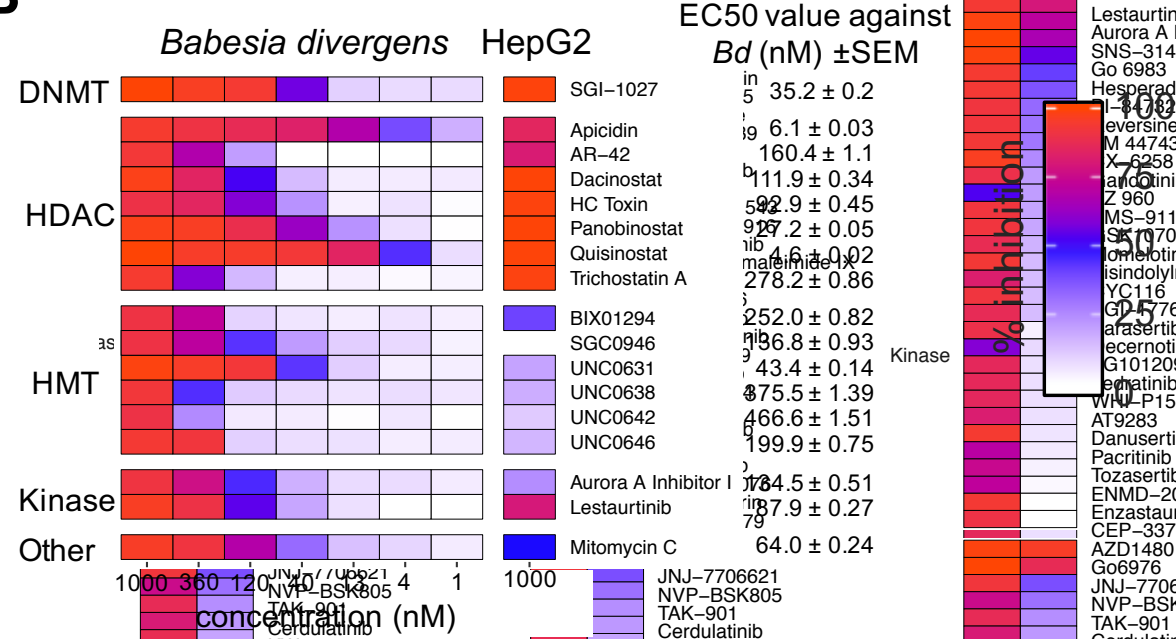

Figure 2. Activity of epigenetic inhibitors against Babesia divergens. (A) 125 compounds with $\geq 50 \%$ inhibition at $10 \mu \mathrm{M}$. Heatmap of mean percent inhibition at 10 and $1 \mu \mathrm{M}$ compared to solvent-treated controls $(n=3)$. Compounds are grouped based on the reported epigenetic process affected in higher eukaryotes: Histone deacetylation (HDAC), histone acetylation (HAT), histone methylation (HMT), Histone Demethylases (HDM), DNA methylation (DNMT), and "Other". (B) Dose response analysis for 17 compounds with submicromolar EC50 values $(n=2)$, with corresponding HepG2 inhibition at $1 \mu \mathrm{M}$. 

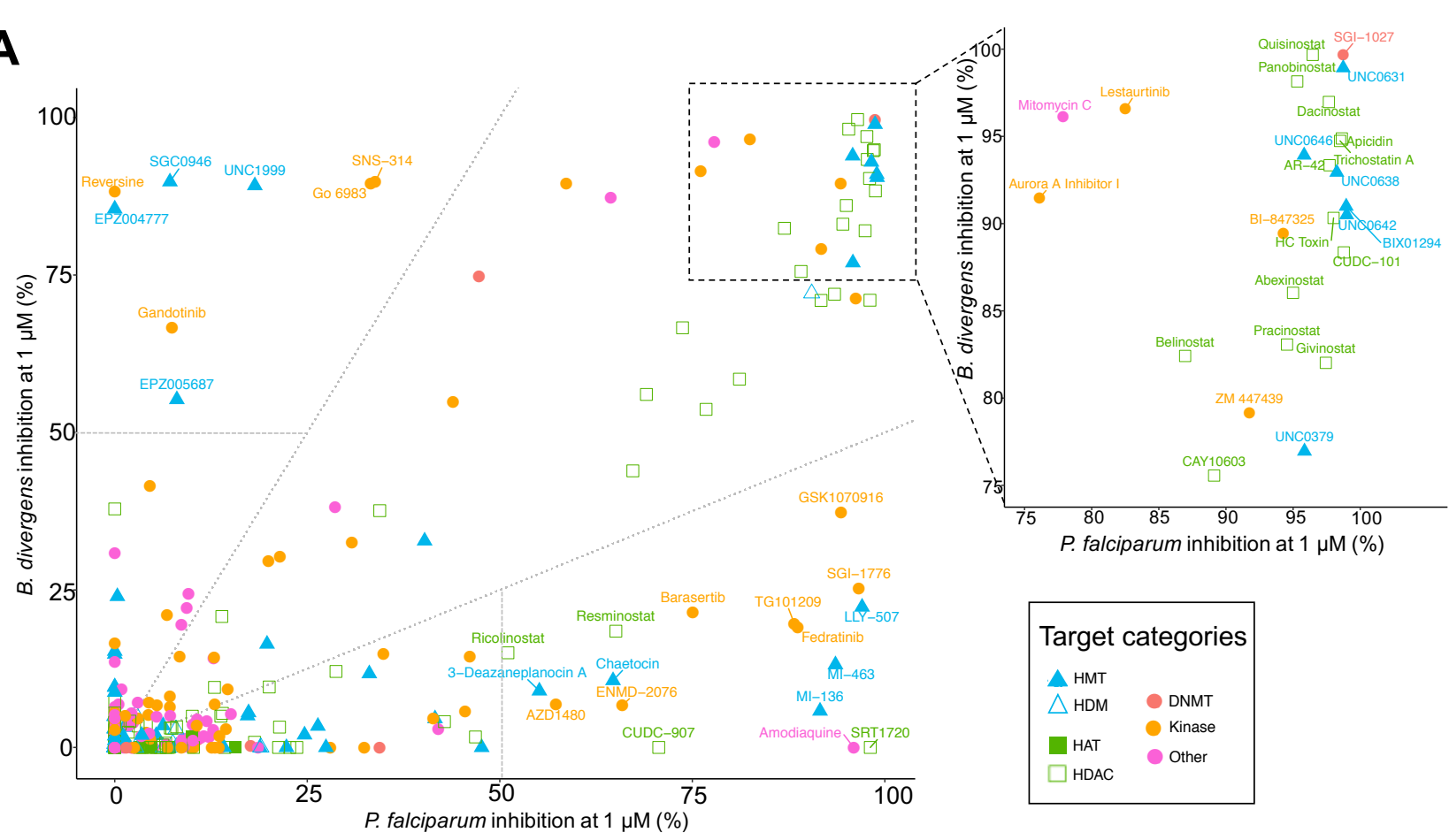

B

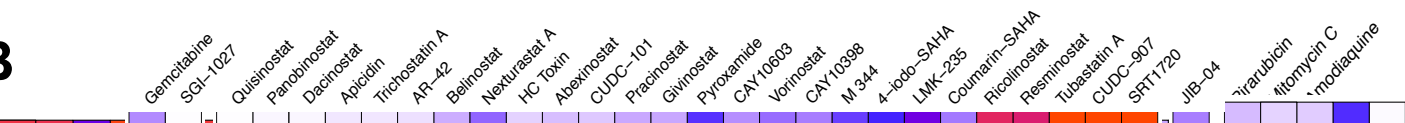

Delta

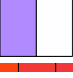

$B d$

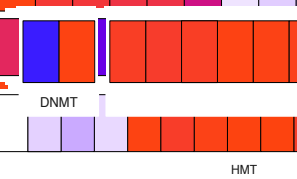

DNMT

HDAC
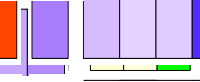

$-100-50 \quad 0 \quad 50100$

$\%$ Delta $(P f-B d)$ inhibition

\section{$P f$}

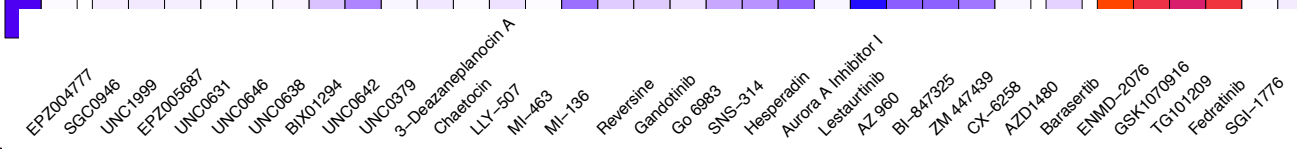

Delta

$B d$

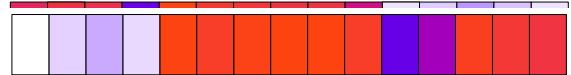

$P f$

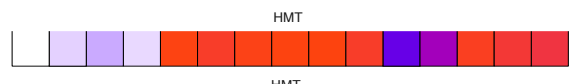

HMT

Kinase

Figure 3. Differential activity of epigenetic inhibitors against $B$. divergens and $P$. falciparum. (A) Scatterplot comparing \%inhibition at $1 \mu \mathrm{M}$ against $B$. divergens and $P$. falciparum. Compound names are indicated for compounds with more than 2-fold difference in activity (dotted lines) and more than $50 \%$ inhibition at $1 \mu \mathrm{M}$ against one species (dashed lines). An enlarged scatterplot with labelled compound names is displayed for compounds with $\geq 75 \%$ at $1 \mu \mathrm{M}$ against both species. (B) Heatmap of compounds with at least $50 \%$ inhibition at $1 \mu \mathrm{M}$ against one species, ordered by the delta activity (\% Pf inhibition - \% Bd inhibition) and grouped by proposed target category. 


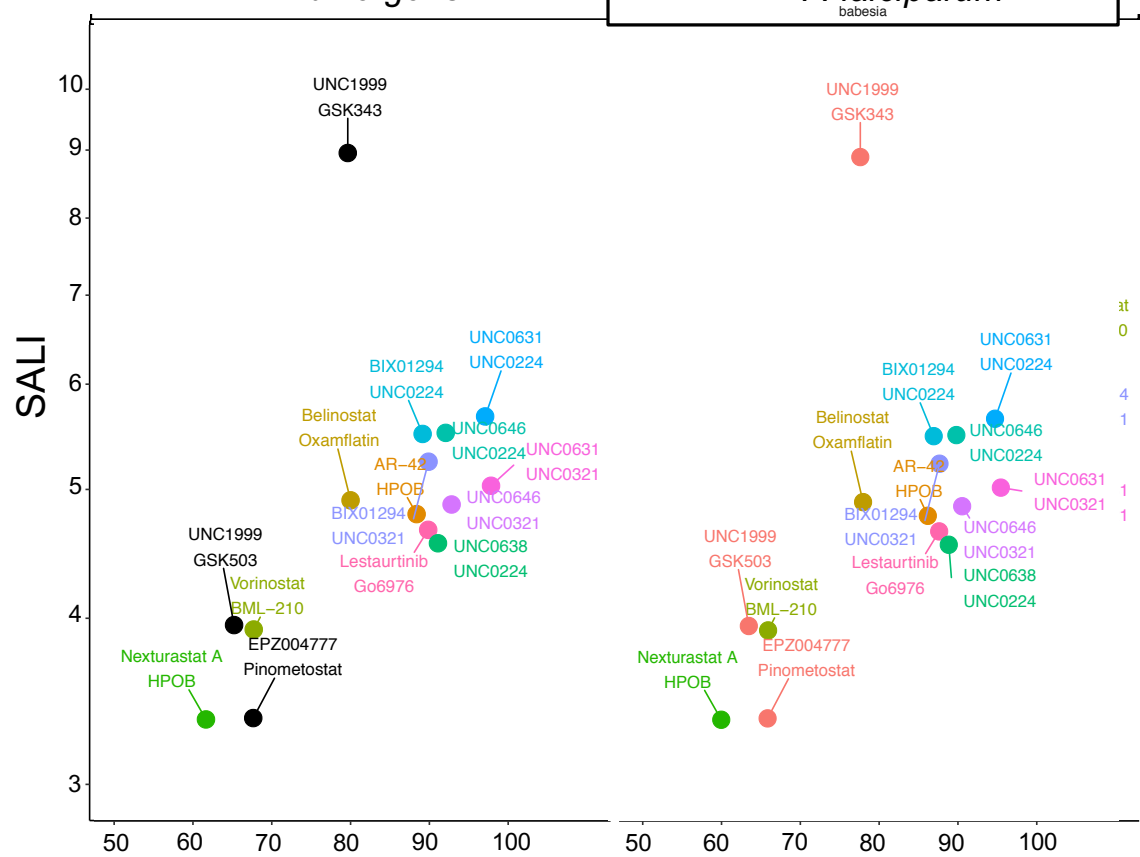

Delta activity (\%)

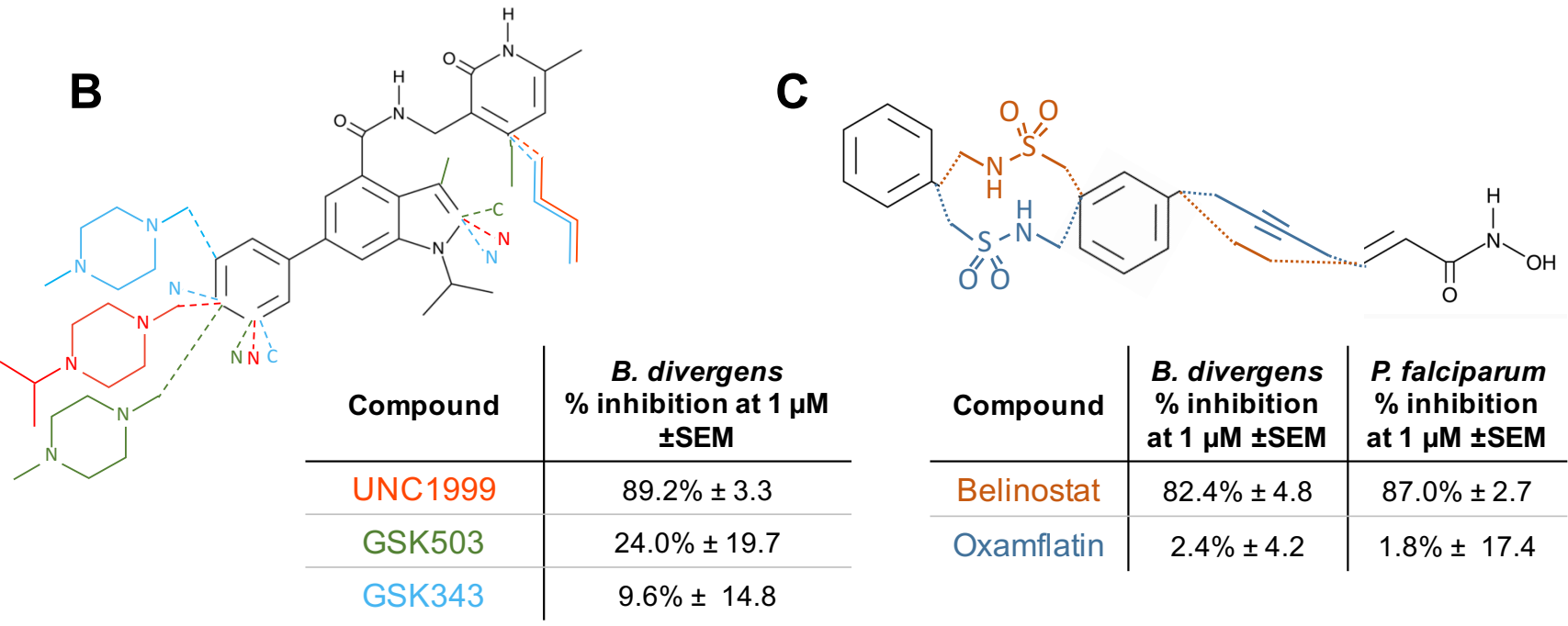

Figure 4. Activity cliff analysis. (A) Scatterplot of 19 activity cliff pairs with $>50 \%$ delta activity and $>80 \%$ structural similarity, grouped by species. Compound pairs that display an activity cliff in both species are indicated in matching colors. (B-C) Examples of activity cliff pairs with respective chemical structures and in vitro activity at $1 \mu \mathrm{M}$. 


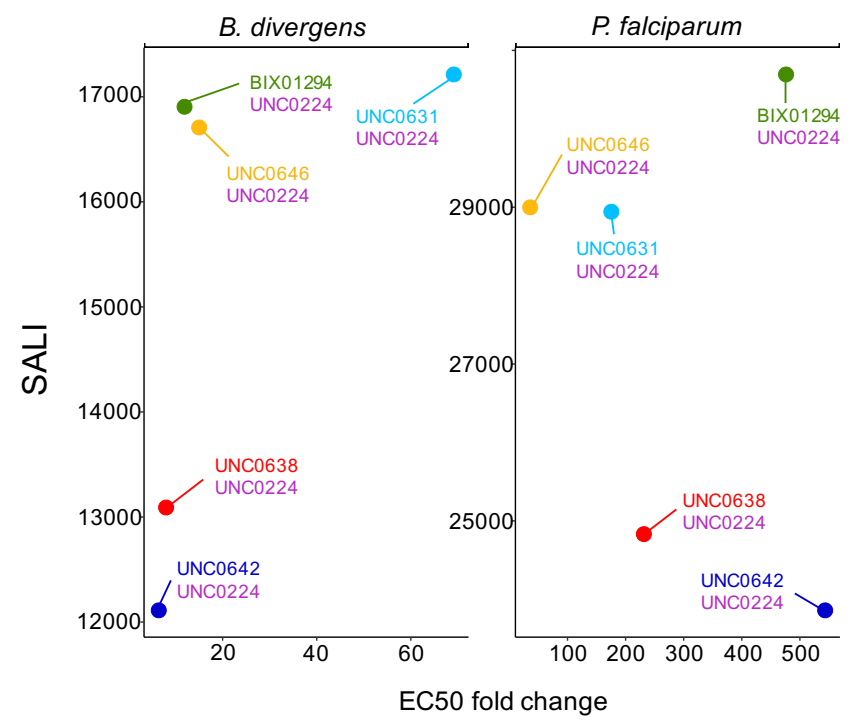

B
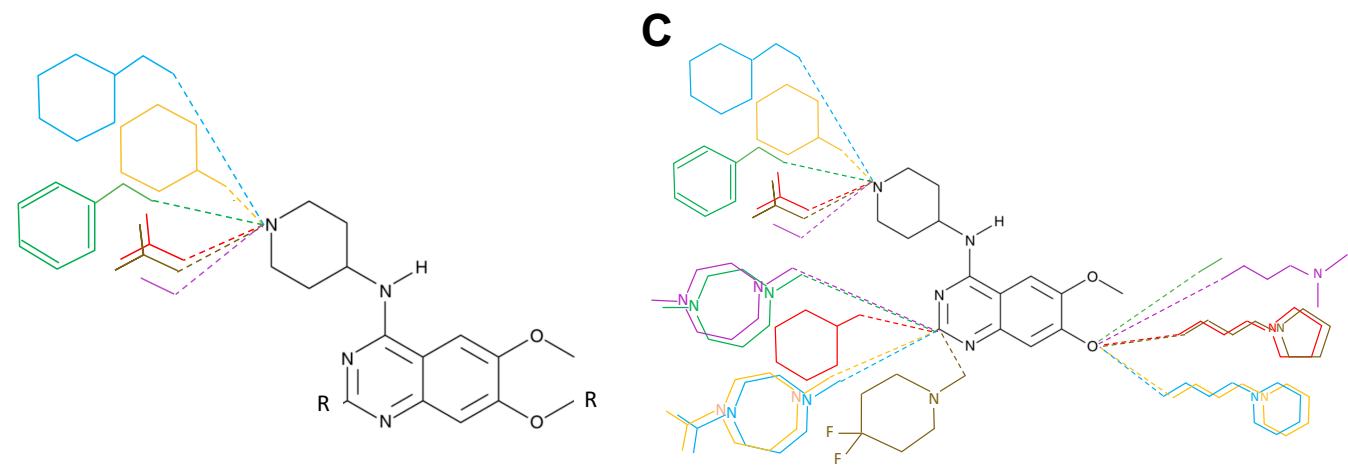

$\left.\begin{array}{c|c}\text { Compound } & \begin{array}{c}\text { B. divergens } \\ \text { EC50 } \pm \text { SEM }\end{array} \\ \hline \text { UNC0631 } & 43.4 \mathrm{nM} \pm 0.1 \\ \text { UNC0646 } & 199.8 \mathrm{nM} \pm 0.8 \\ \text { BIX01294 } & 252.0 \mathrm{nM} \pm 0.8\end{array}\right) \times 5$

\begin{tabular}{c|c|c|c} 
Compound & $\begin{array}{c}\text { B. divergens } \\
\text { EC50 } \pm \text { SEM }\end{array}$ & $\begin{array}{c}\boldsymbol{P} \text { falciparum } \\
\text { EC50 } \pm \text { SEM }\end{array}$ & $\begin{array}{c}\text { B.divergens EC50 / } \\
\text { P.falciparum EC50 }\end{array}$ \\
\hline UNC0642 & $466.6 \mathrm{nM} \pm 1.5$ & $19.2 \mathrm{nM} \pm 10.4$ & 24.3 \\
BIX01294 & $252.0 \mathrm{nM} \pm 0.8$ & $10.5 \mathrm{nM} \pm 3.6$ & 24 \\
UNC0638 & $375.5 \mathrm{nM} \pm 1.4$ & $21.6 \mathrm{nM} \pm 2.0$ & 17.3 \\
UNC0631 & $43.4 \mathrm{nM} \pm 0.1$ & $28.5 \mathrm{nM} \pm 5.9$ & 1.5 \\
UNC0646 & $199.8 \mathrm{nM} \pm 0.8$ & $140.1 \mathrm{nM} \pm 3.8$ & 1.4 \\
UNC0224 & $1-10 \mu \mathrm{M}$ & $1-10 \mu \mathrm{M}$ & 1
\end{tabular}

Figure 5. HMT inhibitors with a diaminoquinazoline backbone. (A) Pairs of diaminoquinazoline compounds with $>60 \%$ similarity and $>50 \%$ delta activity at $1 \mu \mathrm{M}$. (B) Activity of compounds with a diaminoquinazoline backbone against Babesia divergens. (C) Changes in chemical structure that confer differential activity against both species. 


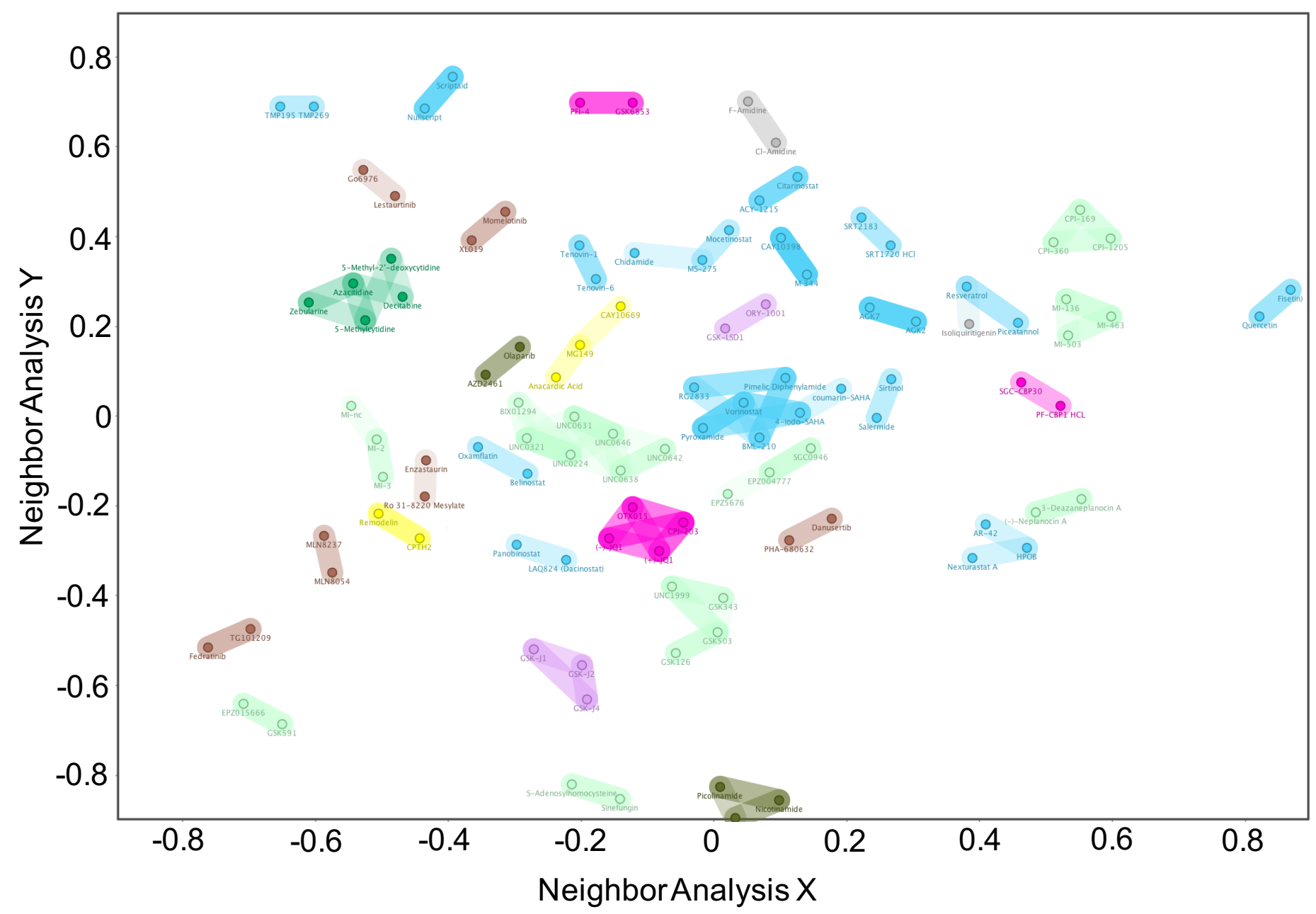

Target Category

OHMT OHAT OOther

OHDM OHDAC OPARP

ODNMT OKinase OHistone Reader

Figure S2. Structural feature similarity landscape. Compounds with $>80 \%$ structural similarity were grouped in Datawarrior (SkelSphere). Color indicates reported epigenetic process targeted in higher eukaryotes. 


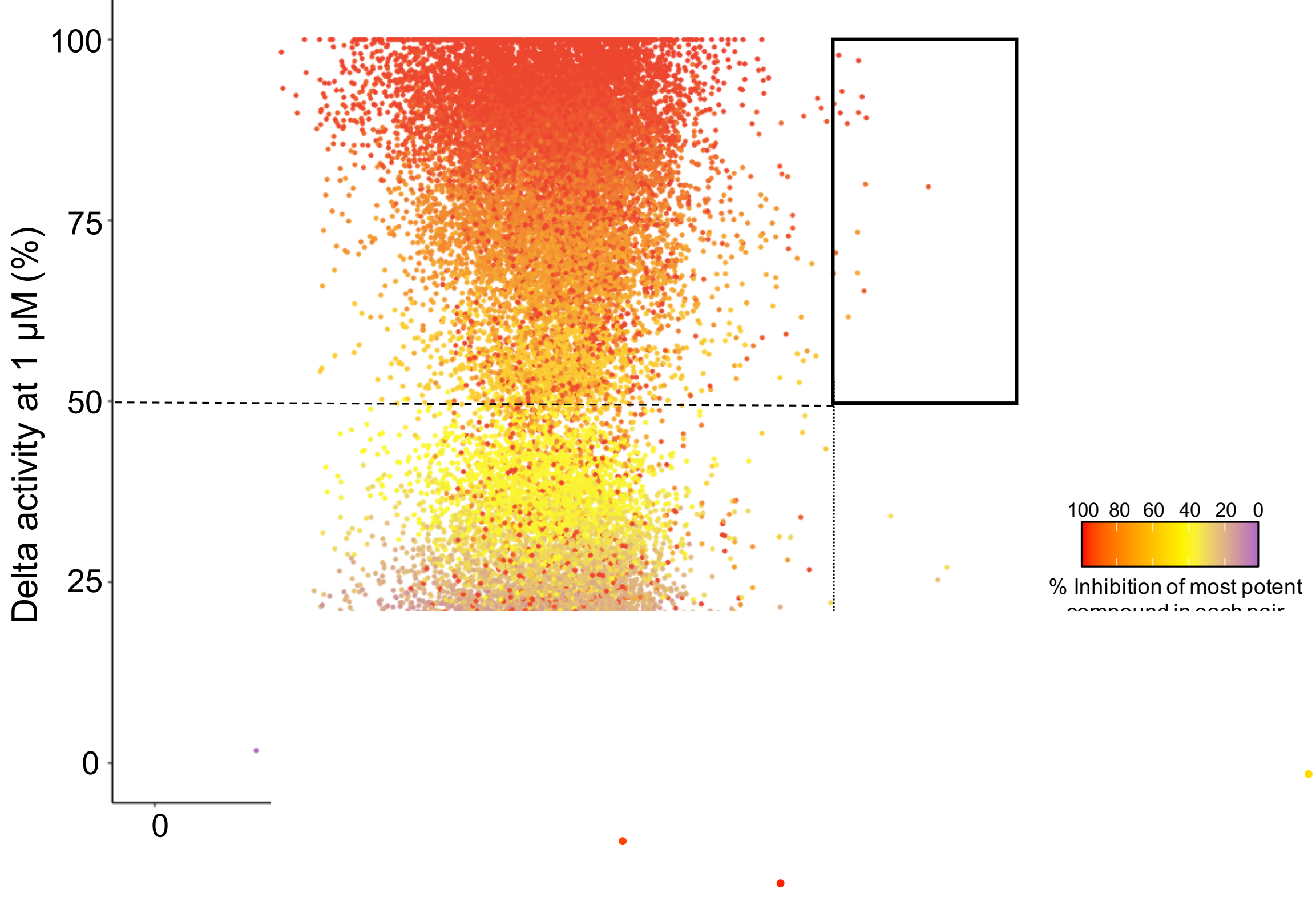

Figure S3. Activity cliff analysis for Babesia divergens at $1 \mu \mathrm{M}$. Scatterplot with each dot representing a pair of compounds in the library. Compound pairs of interest have $\geq 50 \%$ delta activity (dashed line) and $\geq 80 \%$ structural similarity (dotted line). 


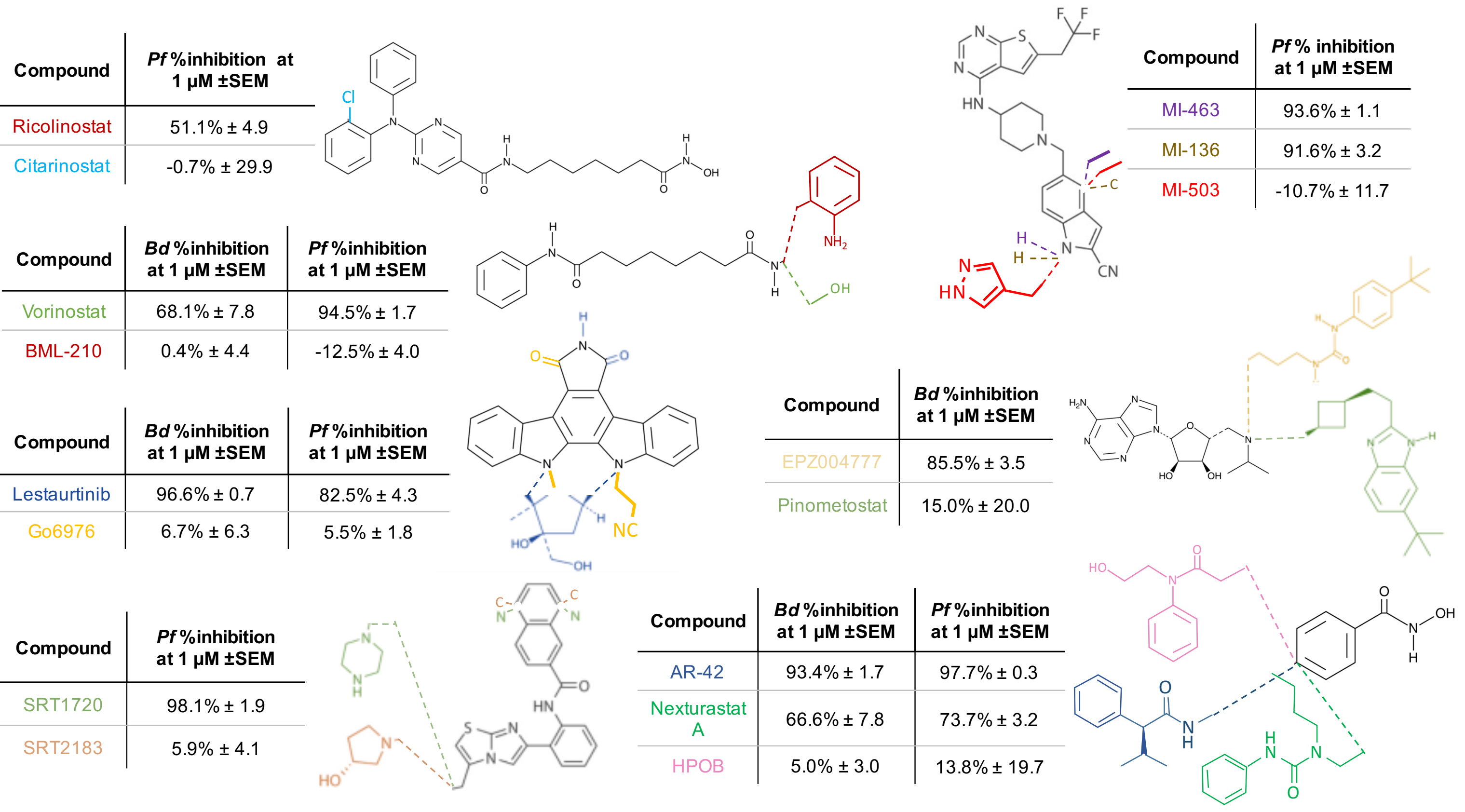

Figure S4. Structural representation of the remaining activity cliff pairs that are displayed in figure $4 \mathrm{~A}$. 

Histone Acetylation Histone Deacetylation Histone Methylation Histone Demethylation Histone Phosphorylation Histone PARPylation Histone Reader Domains DNA Methylation Compounds

B. divergens $P$. falciparum B. divergens $P$. falciparum

Other

Total

\begin{tabular}{|l|r|r|r|r|}
\hline 10 & $0(0 \%)$ & $1(10 \%)$ & $0(0 \%)$ & $0(0 \%)$ \\
85 & $34(40 \%)$ & $43(51 \%)$ & $20(24 \%)$ & $25(29 \%)$ \\
51 & $28(55 \%)$ & $32(63 \%)$ & $10(20 \%)$ & $11(22 \%)$ \\
18 & $4(22 \%)$ & $9(50 \%)$ & $1(6 \%)$ & $1(6 \%)$ \\
66 & $38(58 \%)$ & $41(62 \%)$ & $11(17 \%)$ & $13(20 \%)$ \\
22 & $3(14 \%)$ & $5(23 \%)$ & $0(0 \%)$ & $0(0 \%)$ \\
28 & $12(43 \%)$ & $6(21 \%)$ & $0(0 \%)$ & $0(0 \%)$ \\
14 & $2(14 \%)$ & $3(21 \%)$ & $2(14 \%)$ & $1(7 \%)$ \\
30 & $4(13 \%)$ & $6(20 \%)$ & $2(7 \%)$ & $3(10 \%)$ \\
\hline 324 & $125(39 \%)$ & $146(45 \%)$ & $46(14 \%)$ & $54(17 \%)$ \\
\hline
\end{tabular}

Table ST1. EC50 Activity of epigenetic inhibitors tested grouped by target category. Percentage of active compounds is indicated in brackets $(n=2-3)$.

\begin{tabular}{|c|c|c|c|c|c|}
\hline \multirow[b]{2}{*}{ Target Class } & \multirow[b]{2}{*}{ Compounds } & \multicolumn{2}{|c|}{$>90 \%$ inhibition at $10 \mu \mathrm{M}$} & \multicolumn{2}{|c|}{$>90 \%$ inhibition at $1 \mu \mathrm{M}$} \\
\hline & & B. divergens & P. falciparum & B. divergens & P. falciparum \\
\hline Histone Acetylation & 10 & $0(0 \%)$ & $0(0 \%)$ & $0(0 \%)$ & $0(0 \%)$ \\
\hline Histone Deacetylation & 85 & $25(29 \%)$ & $34(40 \%)$ & $7(8 \%)$ & $15(18 \%)$ \\
\hline Histone Methylation & 51 & $15(29 \%)$ & $19(37 \%)$ & $6(12 \%)$ & $9(18 \%)$ \\
\hline Histone Demethylation & 18 & $4(22 \%)$ & $4(22 \%)$ & $0(0 \%)$ & $1(6 \%)$ \\
\hline Histone Phosphorylation & 66 & $25(38 \%)$ & $25(38 \%)$ & $2(3 \%)$ & $5(8 \%)$ \\
\hline Histone PARPylation & 22 & $1(5 \%)$ & $4(18 \%)$ & $0(0 \%)$ & $0(0 \%)$ \\
\hline Histone Reader Domains & 28 & $1(4 \%)$ & $1(4 \%)$ & $0(0 \%)$ & $0(0 \%)$ \\
\hline DNA Methylation & 14 & $1(7 \%)$ & $1(7 \%)$ & $1(7 \%)$ & $1(7 \%)$ \\
\hline Other & 30 & $3(10 \%)$ & $4(13 \%)$ & $1(3 \%)$ & $1(3 \%)$ \\
\hline Total & 324 & $75(23 \%)$ & $92(28 \%)$ & $17(5 \%)$ & $32(10 \%)$ \\
\hline
\end{tabular}

Table ST2. EC90 Activity of epigenetic inhibitors tested grouped by target category. Percentage of active compounds is indicated in brackets $(n=2-3)$. 